\title{
In-silico ANALYSIS OF 1,3-BIS (p-HYDROXYPHENYL)UREA AS ANTI-INFLAMMATORY THROUGH INHIBITION OF COX-1 AND TNF- $\alpha$
}

\author{
U. Harahap ${ }^{1, \bowtie}$, H. Purnomo ${ }^{2}$ and D. Satria ${ }^{3}$ \\ ${ }^{1}$ Department of Pharmacology, Faculty of Pharmacy, Universitas Sumatera Utara, \\ Medan 20155, Indonesia \\ ${ }^{2}$ Department of Pharmaceutical Chemistry, Faculty of Pharmacy, Universitas Gadjah Mada, \\ Yogyakarta, 55281, Indonesia \\ ${ }^{3}$ Department of Pharmaceutical Chemistry, Faculty of Pharmacy, Universitas Sumatera Utara, \\ Medan 20155, Indonesia \\ Corresponding Author: urip@usu.ac.id
}

\begin{abstract}
A new compound of 1,3-bis(p-hydroxyphenyl) urea was designed and predicted to have fewer hepatotoxic side effects and as analgetic. Synthesis of 1,3-bis(p-hydroxyphenyl) urea could be carried out by reaction between $p$-aminophenol and urea. This study evaluated the mechanism of 1,3-bis(p-hydroxyphenyl) urea in inhibition of COX-1 and TNF- $\alpha$ with molecular docking. Docking was performed on the receptor file COX-1 (PDB ID: 1CQE) and TNF- $\alpha$ (PDB ID: 2AZ5) using AutoDock Vina PyRx 9.5 program and visualized by Ligplot 2.1 and PyMol 2.3.1. Two and threedimension conformation models of compounds were generated by the MarvinSketch program. The docking score of ligand control, 1,3-bis(p-hydroxyphenyl) urea, diclofenac and dexamethasone towards 1CQE and 2AZ5 were -8.4; $10.6 ;-7.4 \mathrm{Kcal} / \mathrm{mol}$ and $-9.2 ;-9.6 ; 7.1 \mathrm{Kcal} / \mathrm{mol}$ respectively. 1,3-bis(p-hydroxyphenyl) urea interacted with more amount of amino acid residues if compare with dexamethasone, diclofenac and ligand control.

Keywords: 1,3-bis(p-hydroxyphenyl) urea, Anti-inflammatory, COX-1, TNF- $\alpha$, In-silico
\end{abstract}

RASĀYAN J. Chem., Vol. 14, No.3, 2021

\section{INTRODUCTION}

Inflammation plays an important role in various diseases. Inflammation is an immunological defense mechanism elicited in response to microbial infections, mechanical injuries, allergens, burns, and another noxious stimulus. ${ }^{1,2}$ Inflammation is a complex process and involves inflammatory cells. Inflammation serves to destroy, reduce, or localize both agents that damage or damaged tissue. Inflammation can be triggered by various factors such as physical, chemical, or biological agents. The "molecular inflammatory" distinguishing molecular changes caused by inflammation itself., Tumor necrosis factor-alpha (TNF- $\alpha$ ) is one of the cytokine that play important role in chronic and acute inflammations through triggers prostaglandins (PG) production, stimulating fever induction, and release the acute inflammation phase proteins such as C-reactive protein (CRP), gene expression of chemokines and cytokines and activating of endothelial cell, contributing in vascular changes for increasing blood flow on the site of the wound. TNF$\alpha$ has another biological activity such as: integrate both innate and adaptive immunities. The cyclooxygenase (COX) enzymes catalyze the bis-oxygenation of free arachidonic acid to $\mathrm{PGH}_{2}$ (the committed step in PG formation). COX-1 is thought to produce PGs which important in homeostasis and role in the inflammation process. ${ }^{5-7}$

A new compound of 1,3-bis(p-hydroxyphenyl) urea was designed and predicted to have less hepatotoxic activity. Synthesis of 1,3-bis(p-hydroxyphenyl) urea could be carried out by reaction between $p$ aminophenol and urea in acidic conditions. The synthetic reaction was given in Fig.-1. 1,3 bis( $p$ hydroxyphenyl)urea is para-aminophenol analogs that were more potent than paracetamol. ${ }^{8,9}$ This aimed of this study to assess the activity of 1,3-bis(p-hydroxyphenyl) urea in inhibition COX-1 and TNF- $\alpha$ expression withIn-silico method. 
RASĀYAN J. Chem.

Vol. 14 | No. 3 |1489-1492| July - September | 2021

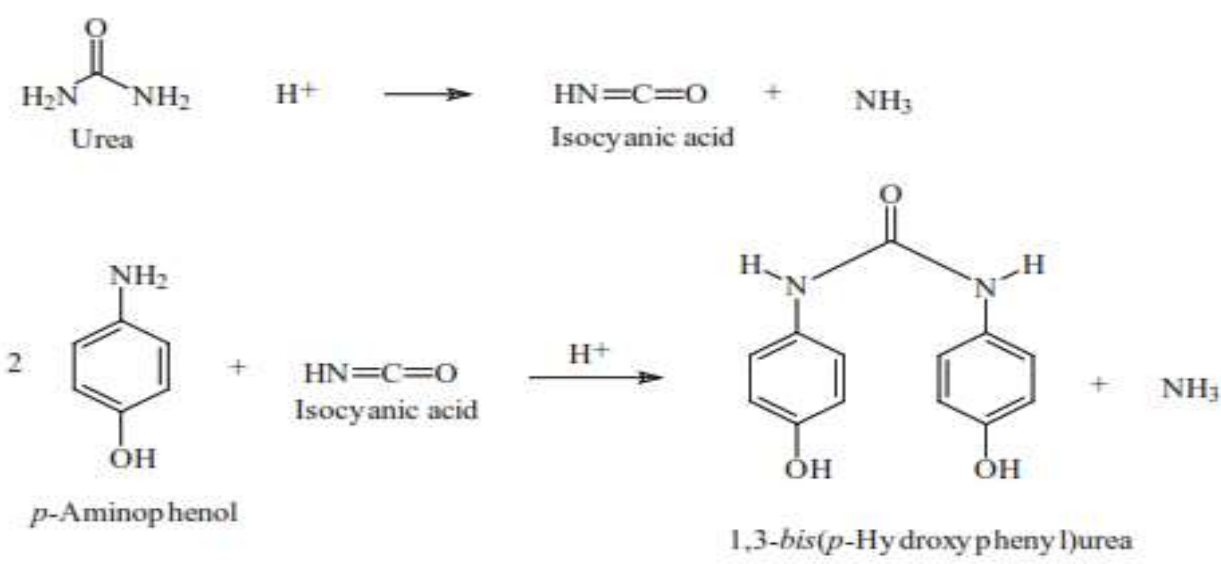

Fig.-1: Synthesis Reaction of 1,3-bis( $p$-hydroxyphenyl) urea

\section{EXPERIMENTAL}

Material and Methods

Aspire Vivobook operated by Windows 7 Home Basic, Intel ${ }^{\circledR}$ CoreTM i5 (3.4 GHz), 64-bit, hard disc drive $320 \mathrm{~GB}$ and RAM 4 GB DDR3 L were used to run the molecular docking process. In-silico docking using Autodock Vina PyRx 9.5 program and visualized by Ligplot 2.1 and PyMol 2.3.1. The model of three dimensions of enzyme structure used in this research was cyclooxygenase-1 (COX-1) and tumor necrosis factor-alpha (TNF- $\alpha$ ) binding pocket with the Protein Data Bank (PDB) code 1CQE and 2AZ5 which were obtained through from http://www.rscb.org/pdb. The Marvin sketch program generates the three-dimension conformation models of control, 1,3-bis-(p-hydroxyphenyl)urea, diclofenac and dexamethasone. ${ }^{10}$

\section{In-silico Analysis}

\section{RESULTS AND DISCUSSION}

In-silico docking control, 1,3-bis-(p-hydroxyphenyl)urea, diclofenac and dexamethasone into the 1CQE and 2AZ5 binding pocket result in the docking score were showed in Table-1 and 2. Figure-1 is showing the results of visualization of control, 1,3-bis-(p-hydroxyphenyl)urea, diclofenac and dexamethasone to COX-1 and TNF- $\alpha$ using PyMol 2.3.1. and Figure 2 and 3 were showed interaction between control, 1,3bis-(p-hydroxyphenyl)urea, diclofenac and dexamethasone towards amino acid residues of COX-1 and TNF- $\alpha$ using Ligplot 2.1 .

Table-1: Binding Affinity of Ligand Standard and Compounds towards COX-1 (1CQE)

\begin{tabular}{c|c|c}
\hline No. & Ligand & Binding Affinity $(\mathrm{Kcal} / \mathrm{mol})$ \\
\hline 1 & Control & -8.4 \\
\hline 2 & 1,3-bis-(p-hydroxyphenyl)urea & -10.6 \\
\hline 3 & Diclofenac & -7.4 \\
\hline 4 & Dexamethasone & -8.8 \\
\hline
\end{tabular}

Table-2: Binding Affinity of Ligand Standard and Compounds towards TNF- $\alpha$ (2AZ5)

\begin{tabular}{c|c|c}
\hline No. & Ligand & Binding Affinity $(\mathrm{Kcal} / \mathrm{mol})$ \\
\hline 1 & Control & -9.2 \\
\hline 2 & 1,3-bis-(p-hydroxyphenyl)urea & $-9,6$ \\
\hline 3 & Diclofenac & -7.1 \\
\hline 4 & Dexamethasone & -8.2 \\
\hline
\end{tabular}

The docking score represents the binding affinity of the ligand to the target protein. The docking of COX1 and TNF- $\alpha$ target with compounds using docking procedure revealed that all the computationally predicted lowest energy complexes of COX-1 and TNF- $\alpha$ are stabilized by intermolecular hydrogen bonds and stacking interactions. Docking score of 1,3-bis-(p-hydroxyphenyl)urea was lower than Diclofenac and Dexamethasone as anti-inflammatory drugs. The results were obtained at $I n$-silico screening have shown that it represents the best step (way) to get an accurate result in a short time and saving manner. ${ }^{8,11-13}$ 
RASĀYAN J. Chem.

Vol. 14 | No. 3 |1489-1492| July - September | 2021

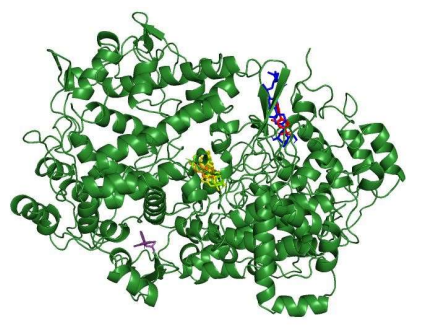

$1 \mathrm{CQE}$

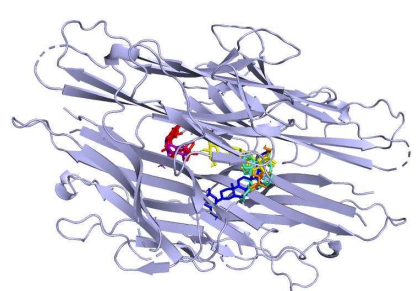

2AZ5

Fig.-1: Three Dimension Binding of Compounds with the Protein Target

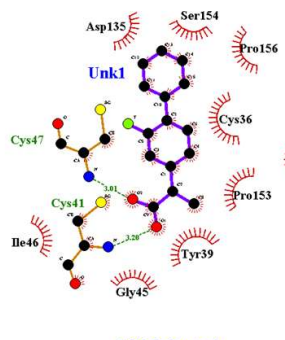

1CQE Control

a

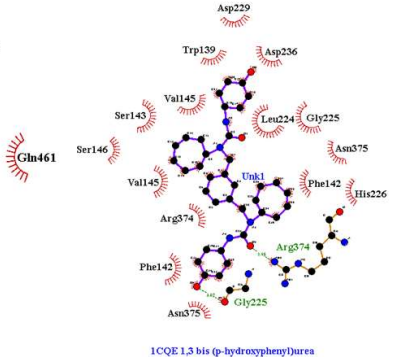

b

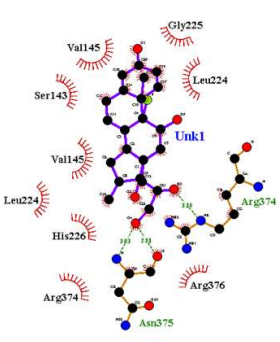

1CQE Dexamethasone

c

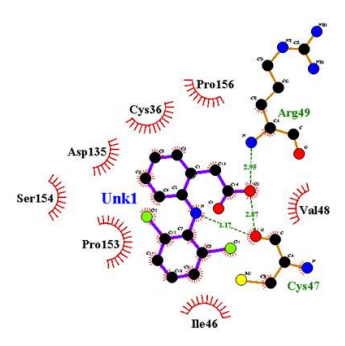

1CQE Diclofenac

d

Fig.-2: Interaction of Compounds with Amino Acids of Protein Target (1CQE)

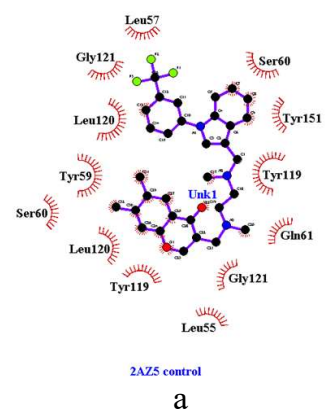

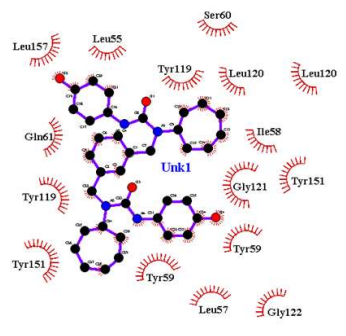

2A75 1,3 bis (p-hydroxypheny)urea

b

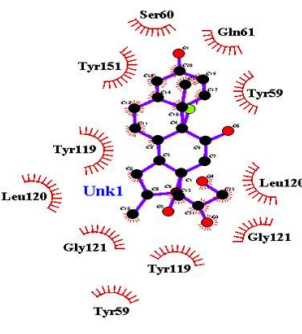

2 AZ5 Dexamethasone

c

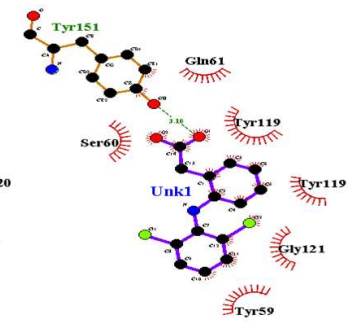

2 AZ5 Diclofenac acid

$\mathrm{d}$

Fig.-3: Interaction of Compounds with Amino Acids of Protein Target (2AZ5)

Table-3: Interaction Ligands and Protein (1CQE) through Amino Acids and the Bond Type

\begin{tabular}{c|c|c|c|c}
\hline Control & 1,3-bis-(p-hydroxyphenyl)urea & Dexamethasone & Diclofenac & Bond Type \\
\hline Asp135 & Ser146 & - & Asp135 & Hydrophobic \\
\hline Ser154 & Ser143 & Ser143 & Ser154 & Hydrophobic \\
\hline Pro156 & Val145 & Val145 & Pro156 & Hydrophobic \\
\hline Cys36 & Trp139 & - & Cys36 & Hydrophobic \\
\hline Gln461 & Asp229 & - & - & Hydrophobic \\
\hline Pro153 & Asp236 & - & Pro153 & Hydrophobic \\
\hline Tyr39 & Leu224 & Leu224 & - & Hydrophobic \\
\hline Gly45 & Gly225 & - & - & Hydrophobic \\
\hline Ile46 & Asn375 & - & - & Hydrophobic \\
\hline- & Phe142 & His226 & - & Hydrophobic \\
\hline- & His226 & - & - & Hydrophobic \\
\hline- & Asn375 & - & - & Hydrophobic \\
\hline- & Phe142 & Arg374 & - & Hydrophobic \\
\hline- & Arg374 & - & - & Hydrogen \\
\hline- & Val145 & Arg374 & Cys47 & Hydrogen \\
\hline Cys47 & Arg374 & - & - & Hydrogen \\
\hline Cys41 & Gly225 & Arg376 & - & Hydrophobic \\
\hline- & - & Asn375 & - & Hydrogen \\
\hline- & - & & &
\end{tabular}

1491 
RASĀYAN J. Chem.

Vol. 14 | No. 3 |1489-1492| July - September | 2021

\begin{tabular}{c|c|c|c|c}
\hline- & - & & Val48 & Hydrophobic \\
\hline- & - & & Arg49 & Hydrogen \\
\hline
\end{tabular}

Table-4: Interaction Ligands and Protein (2AZ5) through Amino Acids and the Bond Type

\begin{tabular}{c|c|c|c|c}
\hline Control & 1,3-bis-(p-hydroxyphenyl)urea & Dexamethasone & Diclofenac & Bond Type \\
\hline Ser60 & Ser60 & Ser60 & Ser60 & Hydrophobic \\
\hline Tyr59 & Tyr59 & Tyr59 & Tyr59 & Hydrophobic \\
\hline Leu120 & Leu120 & Leu120 & - & Hydrophobic \\
\hline Gly121 & Gly121 & Gly121 & Gly121 & Hydrophobic \\
\hline Leu57 & Leu57 & - & - & Hydrophobic \\
\hline Tyr151 & Tyr151 & - & - & Hydrophobic \\
\hline Tyr119 & Tyr119 & Tyr119 & Tyr119 & Hydrophobic \\
\hline Gln61 & Gln61 & Gln61 & Gln61 & Hydrophobic \\
\hline Leu55 & Leu55 & - & - & Hydrophobic \\
\hline- & Leu157 & - & - & Hydrophobic \\
\hline- & Ile58 & - & - & Hydrophobic \\
\hline- & Gly122 & - & - & Hydrophobic \\
\hline- & - & Tyr151 & - & Hydrophobic \\
\hline- & - & - & Tyr152 & Hydrogen \\
\hline
\end{tabular}

CONCLUSION

Based on the research, it can be concluded that 1,3-bis-(p-hydroxyphenyl)urea has higher activity on binding to COX-1 (1CQE) and TNF- $\alpha$ (2AZ5) than control, dexamethasone and diclofenac. This compound is the potential to develop as an anti-inflammatory agent.

\section{ACKNOWLEDGEMENT}

This research was funding by the Ministry of Research and Technology/ National Agency for research and Innovation through the "Hibah Penelitian Dasar (Basic Research)" research grant 2020.

\section{REFERENCES}

1. P. Wojdasiewicz, A. Lukasz, Poniatowski, D. Szukiewicz, Mediators of Inflammation, ID 561459, 1(2014), https://doi.org/10.1155/2014/561459

2. L.M. Sedger, M.F. McDermott, Cytokine and Growth Factor Reviews, 25, 453(2014), https://doi.org/10.1016/j.cytogfr.2014.07.016

3. D. Laveti, M. Kumar, R. Hemalatha, R. Sistla, V.G. Naidu, V. Talla, R. Nagpal, R. Inflamm, Allergy Drug Target, 12(5), 349(2013), https://doi.org/10.2174/18715281113129990053

4. H. Y. Chung, H. J. Kim, K. W. Kim, J. S. Choi and B. P. Yu BP, Microcopy Research \& Technique, 59, 264(2002), https://doi.org/10.1002/jemt.10203

5. L.B. Silva, A.P. Neto, S.M.A.S. Maia, C. Guimaraes, J.C. Leao, The Open Dentistry Journal, 13, 332(2019), https://doi.org/10.2174/1874210601913010332

6. A.A. Khan, M. Ladarola, Hsiu-Ying, T. Yang, R.A. Dionne, The Journal of Pain, 8(4), 349(2007), https://doi.org/10.1016/j.pain.2006.10.004

7. C.J. Smith, Y. Zhang, C.M. Koboldt, J. Muhammad, P. C. Isakson, Proceedings of Natural Academy of Sciences, 95(22), 13313(1998), https://doi.org/10.1073/pnas.95.22.13313

8. H. Purnomo, U.A. Jenie, A.E. Nugroho, H.D. Pranowo, International Journal of Pharmacentical and Clinical Research, 8(5), 367(2016).

9. H. Purnomo, U.A. Jenie, A.E. Nugroho, H.D. Pranowo, JIFI. 14(1), 33(2016).

10. R. A. Syahputra, U. Harahap, A. Dalimunthe, P. Nasution, G. Haro, Widodo, D.H. Utomo, D.Satria Rasayan Journal of Chemistry, 13(2), https://doi.org/10.31788/RJC.2020.1325638

11. A. Syed, N. Fatima, Pharmacognosy Magazine, 11(42), 123(2015), https://doi.org/10.4103/09731296.157712

12. E.N. Bharath, S.N. Manjula, A. Vijaychand, International Journal of Pharmacy and Pharmaceutical Sciences, 3(2), 8(2011).

13. P.A.Z. Hasibuan, P. Sitorus, D. Satria, Asian Journal of Pharmaceutical and Clinical Research, 10(5), 306(2017), https://doi.org/10.22159/ajpcr.2017.v10i5.16931

[RJC-6163/2020] 